University of South Carolina

Scholar Commons

2008

\title{
Breast Health Behavior among Lesbians: The Role of Health Beliefs, Heterosexism, and Homophobia
}

Dana DeHart

University of South Carolina - Columbia, dana.dehart@sc.edu

Follow this and additional works at: https://scholarcommons.sc.edu/sowk_facpub

Part of the Social Work Commons

\section{Publication Info}

Postprint version. Published in Women \& Health, Volume 48, Issue 4, 2008, pages 409-427.

This is an electronic version of an article published in

DeHart, D. D. (2008). Breast health behavior among lesbians: The role of health beliefs, heterosexism, and homophobia. Women \& Health, 48(4), 409-427.

Women \& Health is available online at:

http://www.tandfonline.com/openurl?genre=article\&issn=1541-0331\&volume48\&issue=4\&spage=409

This Article is brought to you by the Social Work, College of at Scholar Commons. It has been accepted for inclusion in Faculty and Staff Publications by an authorized administrator of Scholar Commons. For more information, please contact digres@mailbox.sc.edu. 
POST-PRINT VERSION: DeHart, D. D. (2008). Self-care and use of health services among lesbians: The role of health beliefs, heterosexism, \& homophobia. Women \& Health, 48(4), 409427.

\title{
Breast Health Behavior among Lesbians:
}

\section{The Role of Health Beliefs, Heterosexism, and Homophobia}

\author{
Dana D. DeHart
}

University of South Carolina

Introductory Note: Dr. DeHart, $\mathrm{PhD}$, is a member of the research faculty at The Center for Child \& Family Studies at the University of South Carolina. Please address all correspondence to Dr. DeHart at The Center for Child \& Family Studies, College of Social Work, University of South Carolina, Columbia, SC 29208; e-mail: dana.dehart@sc.edu; phone: 803-777-7867. 


\begin{abstract}
The Health Belief Model was used as a conceptual framework for exploring how health beliefs and perceptions of heterosexism and homophobia in health care relate to lesbians' breast health behaviors, including use of breast exams and mammograms, visits to health care providers, and use of complementary/alternative care. A total of 173 exclusively homosexual women completed survey measures assessing health beliefs, experiences of heterosexism/homophobia, and health maintenance behaviors as these related to breast health. Findings indicated that women perceived heterosexism and homophobia from providers to influence the amount of discussion they had with providers and, to a lesser extent, care received, frequency of service use, and health outcomes. Perceptions of heterosexism and homophobia in health care settings significantly contributed, beyond routine health beliefs, to women's use of breast self-exams, visitation to health care providers, and use of complementary/alternative care. Implications for culturally competent care are discussed.
\end{abstract}

KEYWORDS: breast cancer; breast self-exams; breast health; Health Belief Model; heterosexism; homophobia; lesbians; sexual orientation. 


\title{
INTRODUCTION
}

\author{
I believe progress has been made over the years. However, we need much more in health care \\ providers' knowledge and sensitivity to lesbian health, our needs, and our feelings! (Anonymous \\ respondent)
}

With growing visibility of lesbians in American society, health care providers have increased attention to the unique health interests of this underserved population. Numerous studies have raised concerns about heightened breast cancer risk among lesbians due to nulliparity and behavioral risk factors (Bradford, Ryan, \& Rothblum, 1994; Case et al., 2004; Diamant, 2000; De'Angelis, 1994; Gruskin \& Gordon, 2006; O'Hanlan, 1995). For instance, some researchers found lesbians to have higher 5-year and lifetime risk scores using the Gail Breast Cancer Risk Model (Gail et al., 1989), attributing higher risk largely to reproductive risk factors (Brandenburg et al., 2007; Dibble, Roberts, \& Nussey, 2004). A review found higher behavioral risk among lesbians (e.g., alcohol and tobacco use) but no differences between lesbians and the general population for self-reported breast cancer histories (Cochran et al., 2001). Roberts and associates (2004) found that, although lesbians have increased their use of breast cancer screening behaviors in recent years, they continue to lag behind their heterosexual counterparts. Following from this research, the present study employed a theoretical approach to explore relationships between lesbians' health beliefs, perceptions of heterosexism and homophobia in health care, and use of services and self-care for breast health. Findings will assist providers in promoting access and comfort for lesbian clients via greater understanding of influences on breast health behavior.

\section{Experiences of Heterosexism and Homophobia in Health Care}

In a review of the literature on patient-provider interactions for lesbians, Stevens (1992) noted that a majority of health care providers who responded to surveys held negative attitudes toward lesbians. Although evidence is limited that levels of homophobia may be decreasing among providers (Dinkel et 
al., 2007; Erien, Riley, \& Sereika, 1999), considerable apprehension remains among lesbians about disclosure to providers (Barbara, Quandt, \& Anderson, 2001; Clark et al., 2003; Deevey, 1990; Neville \& Henrickson, 2006; Zeidenstein, 1990). Lesbians continue to experience adverse reactions to disclosing their sexual orientation to health care providers, including ostracism and denial of care (Sinding, Barnoff, \& Grassau, 2004). Concerns about this disclosure may be compounded by proposed legislative initiatives across the U.S. allowing providers to refuse treatment to anyone by citing moral or religious grounds, with gays and lesbians being a "prime target" (Kuhr, 2005).

Conversely, failing to disclose sexual orientation to providers has resulted in women's feelings of invisibility, irrelevant health teaching, and misdiagnoses (Dinkel, 2005; Zeidenstein 1990). The climate of embarrassment and discomfort which surrounds disclosure can undermine or impede development of positive lesbian identity and may deter use of mainstream health care. Researchers have indicated that lesbians are less likely than heterosexual women to use primary care (Roberts et al., 2004) and may be more likely to use complementary and alternative health care or help from friends (Buenting, 1992; Saunders, Tupac, \& MacCulloch, 1988), with homophobia in health care settings noted among reasons for this (Matthews et al., 2005; Plumb, 1994). Complementary and alternative health care with regard to breast health may include taking vitamins and herbs to strengthen immune response, using behavioral methods such as meditation to reduce stress-a known correlate of cancer outcomes (Sephton et al., 2000) — or visiting providers who use therapies outside the purview of conventional medicine such as acupuncture or chiropractic care (Matthews et al., 2005).

Reduced visitation to providers may be especially pertinent to lesbians' gynecological care. That is, many women seek gynecological care—whether from a gynecologist or a primary care provider — mainly for obtaining birth control or prenatal care, needs presumably less prevalent among lesbians than among heterosexually-active women. Further, the context of the gynecological exam, which includes both the breast and pelvic exam, is one in which issues of sexual behavior and sexuality are likely to be addressed. 
Hence lesbians' fears about disclosing sexual orientation may be most germane to this type of care (Johnson \& Guenther, 1987). In past research, over half of lesbians sought gynecological care only when problems were evident (Smith, Johnson, \& Guenther, 1985). Failure to seek gynecological care may delay detection of breast cancers, in that it is during gynecological exams that clinical breast exams or discussion of breast self-exams typically occur. ${ }^{1}$

\section{Need for Theoretical Approaches to Lesbian Health}

The National Research Council's Committee on Lesbian Health Research Priorities developed specific recommendations, emphasizing the need for studies that identify barriers to health care access for lesbians (Solarz, 1999). Although knowledge is growing that establishes baseline data on lesbians' symptomatology and health risks, the current literature lacks research on theoretical underpinnings of lesbian health maintenance. In the literature in medicine, psychology, and social work, only a handful of citations exist on health behavior models as these relate to lesbian health. Some of these focused more on models of education or intervention, such as Washington and Murray's (2005) use community coordination to address breast cancer prevention for Black lesbians or Fobair et al.'s (2002) therapeutic model for women already diagnosed with breast cancer. Identifying barriers to health care access and to use of complementary/alternative care is essential to breast health for lesbian populations. Burnett et al. (1999) selected components of a behavioral model to examine adherence to breast cancer screening guidelines; however, the model was specific to service use, and the sample was an affluent group of women over age 35 with a family history of breast cancer. The researchers found breast cancer worries and employment-related variables to be associated with lesbians' adherence to mammography guidelines, but found no associations to broader adherence including clinical breast exams and breast self-exams. Some of their findings, such as women's low confidence in their own ability to detect abnormalities,

\footnotetext{
${ }^{1}$ Although recent research and media coverage have questioned efficacy of breast self-exam in reducing cancer mortality (Kosters \& Gotzsche, 2008), the issue remains controversial, and evidence suggests that self-exam increases detection of cancers (e.g., Goldstein, 2008; Lam et al., 2008).
} 
indicate that alternate behavioral models and more general lesbian samples may add to understanding of lesbian health maintenance.

The present study addressed the need for a theoretical approach to lesbian breast health behavior. The Health Belief Model (Becker, 1974) has been used successfully for decades to account for health maintenance behaviors in general populations. The model was developed around constructs including perceived benefits of health behavior, perceived barriers to health behavior, perceived severity of health threats, perceived susceptibility to health threats, and cues to action. An example of a benefit would be prevention of disease, while barriers might be comprised of monetary, emotional, or practical impediments to health maintenance. Severity may be perceived as low for more transient threats, such as a common cold, or high for deadly diseases such as AIDS. Susceptibility refers to the individual's perceived vulnerability to a particular health threat. Cues to action are phenomena that encourage the individual to engage in health maintenance; examples of cues include experience of physical symptoms or advice from friends/relatives. A later addition to the model's core concepts was the construct of selfefficacy, or confidence in one's ability to successfully perform the health behavior (Green \& Kreuter, 1999; NCI, 2005). Because lesbians face barriers not extant in heterosexual patient-provider interactions, lesbians' perceptions of heterosexism and homophobia might contribute to breast health behaviors beyond variance contributed by routine health beliefs.

The goal of the present study was to use a theoretical approach in examining lesbians' breast health behaviors. The Health Belief Model was used in conjunction with measures of heterosexism and homophobia in health care to examine the relation between lesbians' beliefs and health maintenance around breast health, including use of breast exams, visits to primary-care and gynecological-care providers, and use of complementary/alternative medicine. Specifically, we explored whether lesbians' breast health behaviors were associated with routine health beliefs and examined whether items addressing perceptions of homophobia and heterosexism in health care were associated with breast health 
behavior beyond variance associated with health beliefs alone.

\section{METHODS}

All study procedures were approved by an institutional review board on research involving human subjects.

\section{Participants}

Participants were a convenience sample of self-identified lesbians surveyed at gay marches and events, scholarly conferences, lesbian nightclubs, and through personal contacts in three Southern cities (Columbia, SC; Louisville, KY; Wilmington, NC). Recruitment methods included booths at events, individual approach by members of the research team, and word-of-mouth by persons who had completed the project survey. Women were invited to participate in a study on lesbian health behavior. All persons wishing to participate received and signed a written informed consent form and completed a fifteenminute paper-and-pencil survey on health attitudes, behaviors, and experiences.

No data are available on number of women who were approached and were not interested in participation, but 100 percent of distributed surveys were returned directly to the researcher $(\mathrm{n}=188)$. Because past research has indicated differences among lesbian and bisexual women with regard to breast health behaviors (Wells et al., 2006), completed surveys were screened by researchers to include only those participants who matched eligibility criteria of self-identifying as a lesbian. Seven percent of respondents identified as bisexual, and one percent identified as asexual; these surveys were excluded from analyses. Ninety-two percent of women currently identified as " homosexual—sexually attracted only to persons of my own sex" and were included in the present analyses $(n=173)$.

Use of convenience sampling is frequently used in research on "hidden" or underserved populations such as lesbians (Bradford, Ryan, \& Rothblum, 1994; Brandenburg et al., 2007). Past research indicates that 
lesbian convenience samples include great diversity with regard to self-identified sexual orientation, years "out," outness/disclosure of sexual orientation to others, sexual experience with women, and lesbian activities (Morris \& Rothblum, 1999). Such variation would present a range of experiences for exploration of relationships between health belief constructs, perceptions of heterosexism/homophobia, and breast health behaviors.

\section{Measures $^{2}$}

\section{$\underline{\text { Health Beliefs about Breast Health }}$}

The survey included nine Likert-type items adapted from past literature (Champion, 1984; Stillman, 1977) to assess perceived benefits, perceived barriers, perceived severity, self-efficacy beliefs, and cues to action as these related to breast health (five-point response range from Not at all to Very much). An additional cue-to-action item tallied persons who had encouraged the woman to practice breast self-exam (providers, partners, friends, and relatives). As a measure of susceptibility, a single item assessed each participant's perception of her own breast cancer risk (5-point rating ranging Less than 1\% to Over 60\%).

\section{(Table 1).}

\section{Breast Cancer Screening, Symptoms, and Diagnoses}

The survey assessed frequency of breast exams including self- and clinical exams (response range: Once a month or more, Every two or three months, Every four to six months, Once a year, and Less than once a year); frequency of mammograms (response range: Once a year or more, Every two or three years, and Less than once every three years). Participants indicated on a checklist whether they had experienced

\footnotetext{
${ }^{2}$ Although surveys addressed a range of health behaviors, analyses for the present paper included only those measures pertinent to breast health. Unless specific citations are provided, measures were developed by the author.
} 
particular symptoms associated with breast cancer and whether they had been diagnosed with malignant lumps or nonmalignant lumps.

\section{Use of Primary-Care and Gynecological-Care Providers}

Participants indicated on a checklist whether they had visited each of the following within the past year: gynecologist, family doctor, public health clinic, hospital emergency room, or other providers. Sex of primary care provider, sex of gynecologist, and whether the woman had health insurance were assessed.

Five-point Likert-type items also assessed the woman's willingness to challenge her provider, whether the provider seemed to take her seriously, whether providers were gentle and concerned versus rough and unconcerned, whether providers told women that problems were psychosomatic, comfort discussing health care with male providers, and comfort discussing health care with female providers.

\section{Use of Complementary and Alternative Care}

To assess complementary/alternative care, a single five-point Likert-type item was used to measure frequency with which participants used "natural health care" to address health problems. An open-ended item allowed participants to list types of natural care used.

\section{Perceptions of Heterosexism \& Homophobia in Health Care}

Participants indicated on five-point Likert-type scales frequency that they believed providers assumed them to be heterosexual, frequency that providers seemed homophobic, how often women disclosed sexual orientation to providers, worry about disclosure, and fear that disclosure would result in substandard care (see Table 1). Participants then indicated on a checklist whether they believed provider assumptions that they were heterosexual affected their health care, their frequency of visitation, the amount of discussion they had with the provider, or their actual health outcomes. A separate checklist was used to indicate whether participants believed provider homophobia affected health care, their 
frequency of visitation, the amount of discussion they had with the provider, or their actual health outcomes. For participants in relationships, a five-point Likert-type item was used to assess provider attention to concerns involving the woman's partner.

\section{Data Analyses}

Quantitative data were analyzed using SPSS statistical software. Descriptive statistics, including mean and median, were conducted on demographic characteristics, and frequencies were run for health behaviors, symptoms, and diagnoses relevant to breast health. Chi-square analyses were conducted to assess distribution of categorical variables, such as having visited male versus female providers. T-tests were used to compare means on Likert-type ratings, including between-group means when the sample was stratified by sex of provider and within-group means in assessing relative ratings on distinct Likerttype items.

Forced-entry hierarchical linear regression analyses were used to assess whether perceptions of heterosexism/homophobia were associated with breast health behavior beyond that associated with core health beliefs constructs. Criterion variables included use of breast self-exams, frequency of breast exams (self or clinical), and use of health care providers (regarding use of ordinal criterion variables in these analyses see: Garson, 2008; Jaccard \& Wan, 1996; Labovitz, 1975; Velleman, 1993). Mammograms were not examined as a criterion variable due to the age-dependent nature of this health behavior (Burnett et al., 1999) and the small number of participants over 40 years of age who could be included in separate analyses. Interactions between variables were not examined. For each of the equations, first the eleven variables representing health beliefs were entered into the equations, followed by a second step in which the five heterosexism/homophobia variables were entered (see Table 1 for items representing these variables). Beta weights were examined, and each equation was refined to include only those variables that displayed alpha values of $\mathrm{p}<0.10$; results are reported for these refined equations. 
Our sample size of 173 persons provided ample power for detecting medium-sized effects using the quantitative analyses herein (Cohen, 1988). Responses to the open-ended prompt on natural care were coded using ATLAS/ti qualitative software.

\section{RESULTS}

\section{Participant Characteristics}

Participants ranged in age from 18 to 74 years, with the median age being 30 . Ninety percent of participants identified as White, 5 percent as Black/African American, 2 percent as Hispanic/Latina, less than 1 percent as Asian/Pacific Islander, less than 1 percent as Native American, and 2 percent identified as "Other." Most participants (84\%) had some college education, and the median annual income for the sample fell in the $\$ 20,000-\$ 29,999$ range.

\section{(Table 2).}

Frequencies were summarized and were stratified by age because some health behaviors and diagnoses might have been age-associated (e.g., mammograms, cancer risks). ${ }^{3}$

\section{Interactions with Providers}

Chi Square analyses were used to examine whether participants reported that their gynecologist was male or female and whether their primary provider was male or female. Participants' gynecologists tended to

\footnotetext{
${ }^{3}$ Because our study included women sampled at nightclubs, and alcohol consumption may be associated with health outcomes, between-groups t-tests and nonparametric median tests were used to assess whether separate analyses were warranted. No differences were observed between participants sampled from nightclubs $(\underline{n}=75)$ and other participants $(\underline{\mathrm{n}}=98)$ in age, education, income, baseline or frequency of mammograms, having visited a health care provider in the past year, frequency of breast exams, or frequencies of reported symptoms/diagnoses.
} 
female, $X^{2}(1)=5.44, \underline{p}<.05$, while their primary providers tended to be male, $X^{2}(1)=4.36, \underline{p}<.05$. Participants indicated on five-point Likert-type scales (range 1 to 5) that they would feel more comfortable discussing health care with female providers $($ mean $=4.48)$ than with male providers $($ mean $=3.18), \underline{\mathrm{t}}(171)=-11.36, \underline{\mathrm{p}}<.001$.

Between-groups t-tests were used to compare ratings by participants who saw male primary providers versus ratings by those who saw female primary providers on Likert-type items. These tests indicated no between-group differences for participants who saw male primary providers versus those who saw female primary providers in ratings of satisfaction with provider services, willingness to challenge providers, experiences of being treated roughly by providers, being taken seriously by providers, being treated as if problems were psychosomatic, having partner needs addressed, provider assumptions of heterosexuality, provider displays of homophobia, frequency of disclosing sexual orientation to providers, worry about disclosure, or fear that disclosure would result in substandard care. Analogous results for ratings on these same variables were obtained when the sample was partitioned to compare between-groups of participants who saw male gynecologists versus those who saw female gynecologists.

Over half of participants thought assumptions of heterosexuality to some degree affected either the care they received from providers, their frequency of visitation to providers, the amount of discussion they engaged in with providers, or actual health outcomes, and about one-third of participants believed homophobia from the provider affected one or more of these things.

\section{(Table 3).}

\section{Analyses of Health Beliefs}

\section{$\underline{\text { Health Beliefs and Breast Exams }}$}

In the first set of regression equations, health belief constructs and homophobia constructs were used to 
examine their associations with use of breast self-exams. First the eleven variables representing health beliefs were entered into the equation, followed by a second step in which the five heterosexism/homophobia variables were entered (see Table 1 for items representing these variables). In the refined equation, only those variables displaying alphas of $\underline{p}<.10$ were included in analyses. This equation included one benefit variable (a lot to gain by doing self exams), self-efficacy (confident with ability to perform self exams), and frequency of disclosing sexual orientation. The benefit and selfefficacy variables accounted for 33 percent of the variance in breast self-exams, $F(2,165)=40.13$, $\underline{p}<$ .001 , and disclosure frequency accounted for an additional 2 percent, $F_{\text {change }}(1,164)=4.68, \mathrm{p}<.05$.

In the second set of equations, health beliefs about breast care and heterosexism/homophobia constructs were used to examine associations with frequency of breast exams including both clinical breast exams and self-exams. First the eleven variables representing health beliefs were entered into the equation, followed by a second step in which the five heterosexism/homophobia variables were entered (see Table 1 for items representing these variables). In the refined equation, only those variables displaying alphas of $\mathrm{p}<.10$ were included in analyses. The refined equation included one barrier variable (embarrassing to do self exams), self-efficacy (confident with ability to perform exams), and worry about disclosure of sexual orientation. The barrier and self-efficacy variables accounted for 20 percent of the variance in frequency of breast exams, $\mathrm{F}(2,163)=20.41, \mathrm{p}<.001$, but the heterosexism/homophobia item did not contribute significantly to the equation, $\mathrm{F}_{\text {change }}(2,162)=.92$, $\underline{\mathrm{ns}}$.

\section{$\underline{\text { Health Beliefs and Primary or Gynecological Care }}$}

The third set of equations used whether the woman had visited any type of health care provider in the past year as a criterion variable. First the eleven variables representing health beliefs were entered into the equation, followed by a second step in which the five heterosexism/homophobia variables were entered (see Table 1 for items representing these variables). In the refined equation, only those variables displaying alphas of $\mathrm{p}<.10$ were included in analyses. The refined equation included one benefit item (a 
lot to gain by doing self exams), self-efficacy (confident with ability to perform exams), worry about disclosure of sexual orientation, and concern disclosing will result in less care. Health belief items accounted for 4 percent of the variance in visitation, $\mathrm{F}(2,165)=3.40, \mathrm{p}<.05$, and heterosexism/homophobia items added another 5 percent, $F_{\text {change }}(2,163)=4.25, \underline{p}<.05$.

\section{Health Beliefs and Complementary/Alternative Care}

About half of participants used complementary/alternative health care to some extent, with types including herbs (12\% of total sample); vitamins (5\%); crystals, oils, or homeopathy (4\%); general health habits such as diet and exercise (3\%); meditation, visualization, or prayer (3\%); acupuncture, massage, or chiropractic care (2\%); and home remedies (2\%).

In a fourth set of regression equations, health belief constructs and heterosexism/homophobia variables were used to examine associations with complementary/alternative health care. First the eleven variables representing health beliefs were entered into the equation, followed by a second step in which the five heterosexism/homophobia variables were entered (see Table 1 for items representing these variables). In the refined equation, only those variables displaying alphas of $\underline{p}<.10$ were included in analyses. The refined equation included one severity item (thought of breast cancer scares me), the susceptibility item (chances of getting breast cancer in lifetime), and one homophobia item (providers have seemed homophobic). Health belief items accounted for 6 percent of the variance in use of complementary/alternative care, $\mathrm{F}(2,156)=4.63, \underline{\mathrm{p}}<.01$, and the homophobia item accounted for an additional 6 percent of the variance, $F_{\text {change }}(1,155)=9.72, \underline{p}<.05$.

\section{DISCUSSION}

This study examined lesbians' health behaviors with regard to breast health. Women's self-reported rates for behaviors, symptoms, and diagnoses related to breast health in the current sample did not appear consistently lower or higher than those found in general samples (Aiello et al., 2004; Fuller et al., 1992; 
Fulton et al., 1991; Reis et al., 2006; Salazar, 1994; Stillman, 1977). Participants visited both male and female providers and were somewhat more comfortable discussing health care with female providers. However, our findings regarding satisfaction and experiences with care are consistent with research that suggests physicians of either gender can provide quality care to lesbians (Boehmer \& Case, 2006).

A primary aim of our study was to use a theoretical approach and examine extent to which health beliefs and perceptions of heterosexism and homophobia were associated with lesbians' breast health. Participants believed that both heterosexism and homophobia from providers affected health maintenance, with the largest perceived impact of each being on the amount of discussion women engaged in with providers. Nearly one-quarter of participants believed that assumptions of heterosexuality by health care providers affected the care the women received. About one in five participants indicated that heterosexism and homophobia from providers influenced how often the women sought health services, while fewer participants felt that these influenced actual health outcomes.

Our regression analyses indicated that lesbians' perceptions of homophobia and heterosexism in health care sometimes contributed beyond routine health beliefs to self-care and use of services. For use of breast exams, this contribution was relatively small, with health belief barriers or benefits, and selfefficacy accounting for the bulk of variance in whether women practiced self-exams and frequency of either clinical or self exams. However, whether women had visited a health care provider in the past year was accounted for by both health belief constructs (benefits and self-efficacy) and by worry and/or beliefs about disclosing sexual orientation to providers. Thus, our theoretical approach indicated that use of mainstream health services might be affected not only by routine health beliefs, but also by inhibitions about disclosing sexual orientation to the professionals.

Perceived homophobia from providers accounted for variance in use of complementary/alternative care within the current sample beyond variance accounted for by health belief constructs. These findings are consistent with Matthews' and associates' (2005) finding that perceived discrimination in health care 
settings may be associated with greater use of complementary and alternative care.

Given that concerns about heterosexism and homophobia did bear a relationship to participants' use of health services, these findings point to opportunities for enhancing culturally competent care. Standards of practice and suggested training components for culturally competent care are described in the Healthy People 2010 Companion Document for Lesbian, Gay, Bisexual, and Transgender Health (GLMA, 2001). Some ways that providers can help lesbian patients feel more comfortable might include using intake forms with options such as "living with domestic partner" as well as "married" and "single," notices on paperwork or waiting areas that the provider does not discriminate on the basis of sexual orientation, providing information of interest to lesbians in waiting areas, and ensuring that questions are open-ended and apply to all patients (e.g., using gender-neutral terms such as "partner"). Culturally competent care might also include gaining the patient's permission before documenting sexual orientation in medical records, developing familiarity with lesbian community referrals, and training office and clinical staff on homophobia and heterosexism (KCPH, 2005). Findings may be of use to practitioners as well as to those developing standards and training programs to reduce heterosexism and homophobia in health care.

A number of limitations of the current study should be noted. First, our findings are not derived from a large, population-based sample; thus, caution should be exercised in generalizing our findings on frequency of health behaviors, symptoms, and diagnoses. Although non-random samples are frequently used in research on underserved populations, our small convenience sample may not have been representative of all lesbians and may limit generalizability of findings. Further, the self-report methodology may have resulted in social-desirability biases. Our measures were adapted and/or researcher-generated, and these measures were kept brief to fit within a broader survey of lesbian health. Reliability and validity of these measures has not been established, and future research using more comprehensive and tested scales is needed to replicate and expand upon these findings. Finally, researchers might use health behavior models to examine lesbians' breast health among more ethnically 
and geographically diverse samples than the current predominantly White, southern sample.

\section{REFERENCES}

Aiello, E., Buist, D., White, E., Seger, D., \& Taplin, S. (2004). Rate of breast cancer diagnoses among postmenopausal women with self-reported breast symptoms. The Journal of the American Board of Family Practice, 17, 408-415.

Barbara, A., Quandt, S., \& Anderson, R. (2001). Experiences of lesbians in the health care environment. Women \& Health, 34(1), 45-62.

Becker, M. (1974). The Health Belief Model and personal health behavior. Thorofare, NJ: Slack.

Boehmer, U., \& Case, P. (2006). Sexual minority women's interactions with breast cancer providers. Women \& Health, 44(2), 41-58.

Bradford, J., Ryan, C., \& Rothblum, E. D. (1994). National Lesbian Health Care Survey: Implications for mental health care. Journal of Consulting and Clinical Psychology, 62, 228-242.

Brandenburg, D., Mattews, A., Johnson, T., \& Hughes, T. (2007). Breast cancer risk and screening: A comparison of lesbian and heterosexual women. Women \& Health, 45(4), 109-130.

Buenting, J. A. (1992). Health life-styles of lesbian and heterosexual women. Health Care for Women International, 13, 165-171.

Burnett, C., Steakley, C., Slack, R., Roth, J., \& Lerman, C. (1999). Patterns of breast cancer screening among lesbians at increased risk for breast cancer. Women \& Health, 29(4), 35-55.

Case, P., Austin, S., Hunter, D., Manson, J., Malspeis, S., Willet, W., \& Spiegelman, D. (2004). Sexual orientation, health risk factors, and physical functioning in the Nurses' Health Study II. Journal of 
Women's Health, 13(9), 1033-1047.

Champion, V. L. (1984). Instrument development for health belief model constructs. Advances in Nursing Science, 73-85.

Clark, M., Bonacore, L., Wright, S., Armstrong, G., \& Rakowski, W. (2003). The cancer screening project for women: Experiences of women who partner with women and women who partner with men. Women \& Health, 38(2), 19-33.

Cohen, J. (1988). Statistical power analyses for the behavioral sciences. Hillsdale, NJ: Erlbaum.

De'Angelis, T. (1994). APA, NIMH discusses gay, lesbian issues. APA Monitor, 25(7), 55.

Deevey, S. (1990). Older lesbian women: An invisible minority. Journal of Gerontological Nursing, $\underline{16(5)}, 35-39$.

Diamant, A.L., Wold, C., Spritzer, K., \& Gelberg, L. (2000). Health behaviors, health status, and access to and use of health care: A population-based study of lesbian, bisexual, and heterosexual women. Archives of Family Medicine, 9, 1043-1051.

Dibble, S., Roberts, S., \& Nussey, B. (2004). Comparing breast cancer risk between lesbians and their heterosexual sisters. Women's Health Issues, 14(2), 60-68.

Dinkel, S.S. (2005). The lived experiences of lesbians over 50 as patients in primary healthcare settings. Doctoral dissertation, University of Missouri, KS.

Dinkel, S., Patzel, B., McGuire, M., Rolfs, E., \& Purcell, K. (2007). Measures of homophobia among nursing students and faculty: A Midwestern perspective," International Journal of Nursing Education Scholarship, 4(1), Article 24. 
Erien, J., Riley, T., \& Sereika, S. (1999). Psychometric properties of the Index of Homophobia Scale in registered nurses. Journal of Nursing Measurement, 7(2), 117-133.

Fobair, P., Koopman, C., Dimiceli, S., O’Hanlan, K., Butler, L., Classen, C., Drooker, N., Davids, H., Loulan, J., Wallsten, D., \& Spiegal, D. (2002). Psychosocial intervention for lesbians with primary breast cancer. Psycho-Oncology, 11(5), 427-438.

Fuller, S. M., McDermott, R. J., Roetzheim, R. G., \& Marty, P. J. (1992). Breast cancer beliefs of women participating in a television-promoted mammography screening project. Public Health Reports, $\underline{107}, 682-690$.

Fulton, J. P., Buechner, J. S., Scott, H. D., DeBuono, B. A., Feldman, J. P., Smith, R. A., \& Kovenock, D. (1991). A study guided by the Health Belief Model of the predictors of breast cancer screening of women ages 40 and older. Public Health Reports, 106, 410-420.

Gail, M., Brinton, L., Byar, D., Corle, D., Green, S., Schairer, C. et al. (1989). Projecting individualized probabilities of developing breast cancer for white females who are being examined annually. Journal of the National Cancer Institute, 81, 1879-1886.

Garson, G. (2008). Data levels and measurement. Retrieved from http://www2.chass.ncsu.edu/garson/PA765/datalevl.htm, April 9, 2008.

Gay and Lesbian Medical Association (2001). Healthy People 2010 companion document for lesbian, gay, bisexual, and transgender (LGBT) health. San Francisco, CA: GLMA.

Goldstein, M. (2008). Breast self-examination (BSE) research and findings update: Recent media story misinforms, omits vital evidence women need to know about. Retrieved from www.mammacare.com on September 9, 2008. 
Green, L.W., \& Kreuter, M.W. (1999). Health promotion and planning : An educational and ecological approach. Mountain View, CA: Mayfield.

Gruskin, E., \& Gordon, N. (2006). Gay/Lesbian sexual orientation increases risk for cigarette smoking and heavy drinking among members of a large Northern California health plan. BMC Public Health, 6, article 241.

Jaccard, J., \& Wan, C. (1996). LISREL approaches to interaction effects in multiple regression. Thousand Oaks, CA: Sage Publications.

Johnson, S. R., \& Guenther, S. M. (1987). The role of "coming out" by the lesbians in the physicianpatient relationship. Women and Therapy, 6, 231-238.

King County Public Health (2005). Culturally competent care for GLBT people: Recommendations for health care providers. Seattle, WA: KCPH.

Kosters, J., \& Gotzsche, P. (2008). Regular self-examination or clinical examination for early detection of breast cancer. Cochrane Database of Systematic Reviews, Issue 3.

Kuhr, F. (August, 2005). Doctor of homophobia: some states may allow health care providers to refuse treatment to anyone, on moral grounds. Gays are a prime target. The Advocate.

Labovitz, S. (1975). Comment to Henkel's paper: The interplay between measurement and statistics. The Pacific Sociological Review, 18(1), 27-35.

Lam, W., Chan, C. P., Chan, C. F., Mak, C., Chan, C. F., Chong, K. W., Leung, M., \& Tang, M. (2008). Singapore Medical Journal, 49(3), 228-32.

Matthews, A., Hughes, T., Osterman, G., \& Kodl, M. (2005). Complementary medicine practices in a 
community-based sample of lesbian and heterosexual women. Health Care for Women International, 26, 430-447.

Morris, J., \& Rothblum, E. (1999). Who fills out a "lesbian" questionnaire? The interrelationship of sexual orientation, years "out," disclosure of sexual orientation, sexual experience with women, and participation in the lesbian community. Psychology of Women Quarterly, 23(3), 537-557.

National Cancer Institute (2005). Theory at a glance. Bethesda, MD: NIH.

Neville, S., \& Henrickson, M. (2006). Perceptions of lesbian, gay, and bisexual people of primary healthcare services. Journal of Advanced Nursing, 55(4), 407-415.

O'Hanlan, K. A. (1995). What are lesbian health issues? Advocate, 676, 48-49.

Plumb, M. (1994). Lesbian health overview and policy issues. Cancer and Cancer Risk Among Lesbians: Proceedings of an Interactive Working Conference, Community Liaison Program, Fred Hutchinson Cancer Research Center, Seattle, WA.

Ries, L., Melbert, D., Krapcho, M., Mariotto, A., Miller, B., Feuer, E., Clegg, L., Horner, M., Howlader, N., Eisner, M., Reichman, M., \& Edwards, B. (2006). SEER cancer statistics review, 1975-2004. Bethesda, MD: National Cancer Institute.

Roberts, S., Patsdaughter, C., Grindel, C., \& Tarmina, M. (2004). Health related behaviors and cancer screening of lesbians: Results of the Boston Lesbian Health Project II. Women \& Health, 39(4), $41-55$.

Salazar, M. K. (1994). Breast self-examination beliefs: A descriptive study. Public Health Nursing, 11, 49-56.

Saunders, J. M., Tupac, J. D., \& MacCulloch, B. (1988). A lesbian profile: A survey of 1000 lesbians. 
West Hollywood, CA: Southern California Women for Understanding.

Sephton, S., Sapolsky, R., Kraemer, H., \& Spiegel, D. (2000). Diurnal cortisol rhythm as a predictor of breast cancer survival. Journal of the National Cancer Institute, 92(12), 994-1000.

Sinding, C., Barnoff, L., \& Grassau, P. (2004). Homophobia and heterosexism in cancer care: The experiences of lesbians. Canadian Journal of Nursing Research, 36(4), 170-188.

Smith, E. M., Johnson, S. R., \& Guenther, S. M. (1985). Health care attitudes and experiences during gynecological care among lesbians and bisexuals. American Journal of Public Health, 75, 10851087.

Solarz, A. (1999). Lesbian health: Current assessment and directions for the future. Washington, DC: National Academy.

Stevens, P. E. (1992). Lesbian health care research: A review of the literature from 1970 to 1990. Health Care for Women International, 13, 91-120.

Stillman, M. J. (1977). Women's health beliefs about breast cancer and breast self-examination. Nursing Research, 26, 121-127.

Velleman, P. (1993). Nominal, ordinal, interval, and ratio typologies are misleading. The American Statistician, 47(1), 65-72.

Washington, T., \& Murray, J. (2005). Breast cancer prevention strategies for aged Black lesbian women. Journal of Gay \& Lesbian Social Services, 18(1), 89-96.

Wells, B., Bimbi, D., Tider, D., Van Ora, J, \& Parsons, J. (2006). Preventative health behaviors among lesbian and bisexually identified women. Women \& Health, 44(2), 1-13. 
Zeidenstein, L. (1990). Gynecological and childbearing needs of lesbians. Journal of Nurse-Midwifery, $\underline{35}, 10-18$. 


\title{
Table 1: Items Assessing Health Beliefs and Heterosexism/Homophobia
}

\author{
Beliefs about Breast Heath
}

BENEFIT: I have a lot to gain by doing self breast exams. [5-point scale Not at all to Very much ]

BENEFIT: I believe it is possible to detect breast cancer at an early stage. [5-point scale]

BARRIER: It is embarrassing for me to do self breast exams. [5-point scale]

BARRIER: Doing self breast exams would interfere with my activities. [5-point scale]

SEVERITY: The thought of breast cancer scares me. [5-point scale]

SEVERITY: Breast cancer is a hopeless disease. [5-point scale]

SELF-EFFICACY: I feel confident with my ability to effectively perform self breast exams. [5-point scale]

CUE: My friends, partner(s), or relatives talk about breast cancer. [5-point scale]

CUE: I have heard about breast cancer from television, films, or pamphlets. [5-point scale]

CUE: ___ Has encouraged me to engage in home breast exams [checklist: health provider, partner/spouse, relatives, friends, other; coded cumulative number who encouraged].

SUSCEPTIBILITY: The chances of my getting breast cancer sometime during my lifetime are $[5-$ point rating ranging Less than $1 \%$ to Over $60 \%$ ].

Perception of Heterosexism/Homophobia in Care

My health care providers have assumed that I am heterosexual. [5-point scale] 
My health care providers have seemed homophobic. [5-point scale]

I tell health care providers about my sexual orientation. [5-point scale]

I worry about "coming out" to a health care provider. [5-point scale]

If I "come out" to a health care provider, they won't treat my problems with as much care. [5-point scale] 
Table 2: Frequencies of Reported Health Behaviors and Diagnoses

$\begin{array}{llll}\text { Behavior } & \text { TOTAL } & \text { Age }<40 \text { years } & \text { Age } 40 \text { years \& over } \\ & (\mathrm{n}=173) & (\mathrm{n}=131) & (\mathrm{n}=26)^{4} \\ \text { Ever practice self-exam } & 70 \% & 67 \% & 89 \% \\ \text { Ever had a clinical breast exam } & 85 \% & 81 \% & 100 \% \\ \text { Monthly self-exam } & 19 \% & 21 \% & 12 \% \\ \text { Ever had mammogram } & & & 89 \% \\ \text { Primary care in past year } & 38 \% & 26 \% & 69 \% \\ \text { Any provider in past year } & 60 \% & 57 \% & 88 \% \\ \text { Have health insurance } & 86 \% & 85 \% & 69 \%\end{array}$

Symptoms

Breast pain

$18 \%$

$17 \%$

$27 \%$

Breast lumps

$13 \%$

$11 \%$

$27 \%$

Discharge from nipples

$3 \%$

$3 \%$

$4 \%$

Nodes under armpits

$4 \%$

$4 \%$

$4 \%$

Dimpling or distorted contour

$2 \%$

$3 \%$

$0 \%$

\footnotetext{
${ }^{4}$ Sixteen women who did not provide their age were included in overall analyses but not in age-stratified analyses.
} 
Breast Health pg. 27 of 28

Any symptoms above

$\underline{\text { Diagnoses }}$

Breast cancer

$2 \%$

$1 \%$

$8 \%$

Nonmalignant lumps

$16 \%$

$12 \%$

$27 \%$ 


\section{Table 3: Women's Beliefs about Heterosexism/Homophobia}

$\%$ of total sample $(\mathrm{n}=173)$ responding affirmatively

$80 \%$

My health care providers have assumed that I am heterosexual

Your health care

$19 \%$

How often you see a provider

$45 \%$

Amount of discussion you have with providers

$10 \%$

Your health outcomes

$53 \%$

Any of the above effects

$59 \%$

My health care providers have seemed homophobic

This affects:

Your health care

$16 \%$

How often you see a provider

$21 \%$

Amount of discussion you have with providers

$29 \%$

Your health outcomes

$7 \%$

Any of the above effects

$32 \%$ 